\title{
New Mechatronics Curriculum on Multi-axis Industrial Motion Control
}

\section{Prof. Hakan Gurocak, Washington State University, Vancouver}

Prof. Gurocak is the founding director of School of Engineering and Computer Science at Washington State University Vancouver. His research interests include haptics, robotics and automation.

\section{Dr. Ashley Ater Kranov, Washington State University}

As Vice President of GPS Assessment, LLC, Dr. Ater Kranov leads an international team of professionals from academia and industry to build capacity of individuals and organizations in the following areas: Educational Research, Quality Assurance, Optimizing Student Learning, and Leadership Skills.

Dr. Ater Kranov is also adjunct associate professor in the School of Electrical Engineering and Computer Science at Washington State University. 


\title{
NEW MECHATRONICS CURRICULUM ON MULTI-AXIS INDUSTRIAL MOTION CONTROL
}

\begin{abstract}
Over the past couple decades, mechanical engineering programs have made significant advances in developing educational materials and laboratory exercises in controls and mechatronics ${ }^{1-4}$. However, there is an important gap remaining between the academic programs and the needs of the graduates and industry. The academic programs are heavily oriented towards control theory, board-level electronics, interfacing and microprocessors supplemented with laboratory equipment, such as the inverted pendulum, and projects, such as Lego robots ${ }^{5-7}$. But industrial applications require mechanical engineers to design machines with multiple axes that execute complex, high speed, high precision coordinated motion using sophisticated motion controllers. In this paper, we present overview of a new course and its laboratory developed in partnership with industry. The course aims to teach "the fundamentals" while focusing on industrial motion control technology and multi-axis machines. The course was offered for the first time in its new format in Fall 2013. Assessment results for one module are presented and discussed. This project was funded by a grant from the NSF-TUES program.
\end{abstract}

\section{Introduction}

Industrial applications require mechanical engineers to design machines with multiple axes that execute complex, high speed, high precision coordinated motion using sophisticated motion controllers. To design such systems students need to learn the industrial motion control technology; be able to bring together control theory, kinematics, dynamics, electronics, simulation, programming and machine design; apply interdisciplinary knowledge; and deal with practical application issues. Due to the current compartmentalized approach used in teaching these subjects and the emphasis on mathematical algorithms and board-level applications, most new mechanical engineering graduates are unable to meet the industry expectations.

Motion control is a sub-field of automation in which the position and/or velocity of multiple axes in a machine are controlled in a synchronized fashion. Motion control is widely used in all types of industries including packaging, assembly, textile, paper, printing, food processing and semiconductor manufacturing (Figure 1).

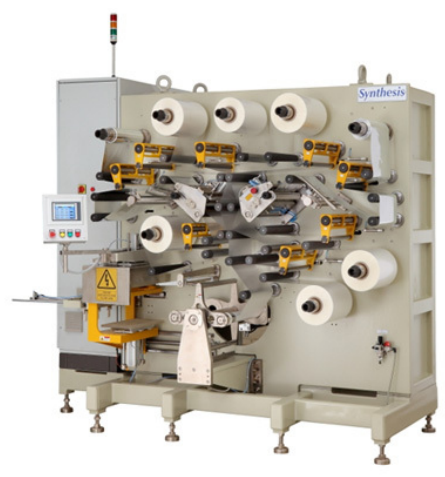

(a)

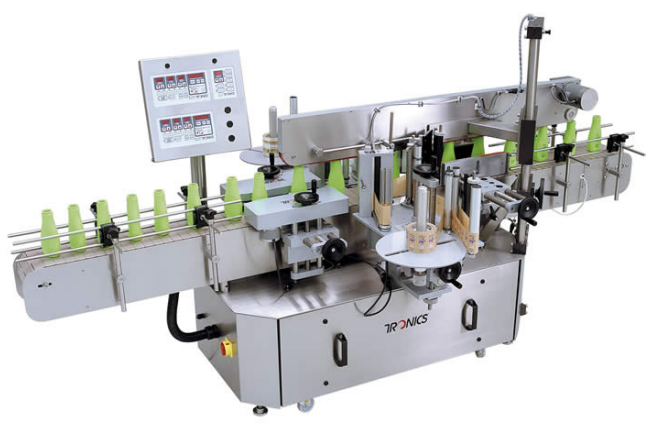

(b)

Figure 1. Multi-axis machines with industrial motion controller (a) Web handling (winding) machine, (b) Labeling machine. 
The complete motion control system consists of (1) a motion controller that generates complex multi-axis motion profiles and closes feedback loops on each axis, (2) drives for high power signals for motors, (3) different types of motors, (4) feedback sensors, and (5) mechanical transmission elements (gears, belts, lead screws) to transform motion of the motors into the desired motion of the axes.

Most universities offer controls, or mechatronics or both at the undergraduate level to address the need for automation education. The controls courses are heavily theoretical involving advanced mathematical concepts. The mechatronics courses use small DC brush motors, introduce basic electronics (OpAmps, transistors, LEDs, etc.), interfacing circuits and programming microprocessors at the board level. Laboratory equipment or projects involve educational lab hardware such as balancing an inverted pendulum (Figure 2a,b) or a ball-on-beam or LEGO robots (Figure 2c) following lines, solving a maze.

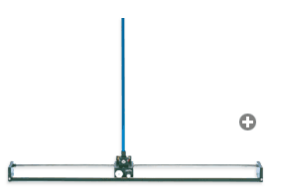

(a)

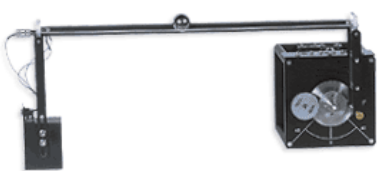

(b)

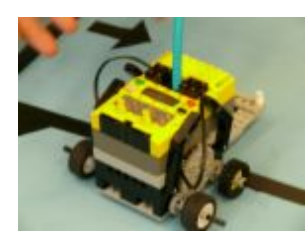

(c)

Figure 2. Sample typical lab equipment used at universities. (a) Inverted pendulum, (b) ball-andbeam, (c) LEGO robot.

While these platforms provide a great way to explore control algorithms, they do not go beyond academic exercises. We use these platforms to "teach the fundamentals" in the courses and let them learn the industrial hardware after graduation. Industry needs mechanical engineers who can do system design and integration using motion controllers and Programmable Logic Controllers (PLC) as the primary building blocks for automation/mechatronics applications. They are not expected to design controllers, control algorithms or interface electronic circuits at the board level or program microprocessors.

In this curriculum development effort, our goal was to complement the existing controls and mechatronics curricula. We aimed to "teach the fundamentals", but in the context of industrial motion control technology to address the gap.

In this paper, we present an overview of a new modular curriculum designed in collaboration with industry to "teach the fundamentals", but in the context of industrial motion control technology and multi-axis machines. The details of one of its modules along with assessment results and feedback from students have also been presented.

\section{Overview of the new curriculum}

The new curriculum is centered on multi-axis industrial motion control. Our primary goal was to integrate separately taught subjects of abstract control theory, kinematics, dynamics, electronics, programming and machine design in the context of industrial motion control. The instructional design includes active learning components in the lectures and competency-based lab modules. 
Table 1 provides a brief listing of the curriculum modules that have been under development. In the next section we present details of one of the modules.

Table 1. New course curriculum.

\begin{tabular}{|c|c|c|}
\hline & Module & Content \\
\hline 1 & Path generation & Position, velocity, acceleration profiles \\
\hline 2 & Drive-train design & $\begin{array}{l}\text { Motor and gearbox selection, transmission elements } \\
\text { including gears, belts, lead screws, etc. }\end{array}$ \\
\hline 3 & Electric drives & $\begin{array}{l}\text { Motion controller details: Dynamic system models } \\
\text { with transfer functions, PID control algorithm, AC } \\
\text { servomotor operation }\end{array}$ \\
\hline 4 & Tuning & $\begin{array}{l}\text { Practical tuning rules for PID gains, position control } \\
\text { system simulations }\end{array}$ \\
\hline 5 & Motion control applications & $\begin{array}{l}\text { Multi-axis coordinated motion, master/slave axis } \\
\text { coordination, web handling control architectures, } \\
\text { flying saw applications }\end{array}$ \\
\hline 6 & Sensors & Incremental and absolute encoders \\
\hline
\end{tabular}

\section{Path generation module}

When an axis of a machine needs to move from point A to B, the path (trajectory) connecting points A and B needs to be computed. This trajectory needs to result in a smooth acceleration of the axis from point $\mathrm{A}$ to a constant operational speed and finally smoothly decelerate to come to a stop at point B. This module explores the details of how such a trajectory is generated in industrial motion controllers. Table 2 provides details of the module.

\section{III.1. Active learning}

During the lectures, after introducing a concept, the presentation was stopped and we switched to an active learning (think-pair-share) exercise for 2-5 minutes. These exercises were called "Your Turn".

The students were given a question on the material just covered and asked to work on it with their friend sitting next to them. When the time was up, the instructor asked for answers to the question and, in many cases, a lively discussion took place with enthusiastic participation from the students. Then, the solutions were distributed to the class. The lecture presentation was resumed for about 10 minutes to arrive at another "your turn" exercise in the lecture. This process was repeated throughout the semester.

Each "your turn" question was designed to emphasize a certain concept. Sometimes this mechanism was used to ensure that the students understood a difficult concept. It also gave a chance for the students to ask "what-if" questions to explore the concept further with the instructor and the other students in class. The downside of this activity is that it takes away from the lecture time. It was a trade-off since on one hand it enabled deeper learning while on the other hand it somewhat reduced the amount of material included in the lectures. 
Table 2. Path generation module.

\begin{tabular}{|c|c|c|}
\hline & Topic & Content \\
\hline 1 & $\begin{array}{l}\text { Kinematics: A brief review of } \\
\text { basic concepts }\end{array}$ & $\begin{array}{l}\text { Kinematic relationships between position, velocity, } \\
\text { acceleration; graphical representations; examples }\end{array}$ \\
\hline \multirow[t]{4}{*}{2} & Common motion profiles & 2.1. Trapezoidal velocity profile \\
\hline & & $\begin{array}{l}\text { Derivation of kinematics formulas for position, } \\
\text { velocity and acceleration profiles; examples } \\
\text { using Excel }\end{array}$ \\
\hline & & 2.2. S-curve velocity profile \\
\hline & & $\begin{array}{l}\text { Derivation of kinematics formulas for position, } \\
\text { velocity and acceleration profiles; examples } \\
\text { using Excel and MATLAB }\end{array}$ \\
\hline \multirow[t]{4}{*}{3} & Multi-axis motion & 3.1. Slew motion \\
\hline & & $\begin{array}{l}\text { Uncoordinated motion of individual axes of a } \\
\text { machine. Solved examples of motion profiles }\end{array}$ \\
\hline & & 3.2. Interpolated motion \\
\hline & & $\begin{array}{l}\text { Coordinated motion of individual axes of a } \\
\text { machine (such as linear and circular motion). } \\
\text { Solved examples of motion profiles }\end{array}$ \\
\hline
\end{tabular}

\section{Laboratory}

The course has a weekly 150-minute laboratory session. The primary goal of the laboratory is to provide hands-on experience with industrial-grade automation equipment and with a state-of-theart multi-axis industrial motion controller.

Seven laboratory stations have been designed and built. Each station has a control panel, which contains the controller, power supplies and I/O terminals, buttons and indicator lights. The panels have been custom designed in collaboration with a local industrial panel shop. The wiring follows the industrial professional practice found in any commercial machine. Figure 3 shows one of the panels.

Each machine has been custom designed and built at the university. The machines are miniaturized versions of the real industrial machines. Industrial grade components such as sensors, motors, bearings, cabling, etc. were used in the designs. As such, each station contains the same industrial control panel that would be found in industry but interfaced to a miniaturized industrial machine. Figure 3 shows some of our laboratory machines. 


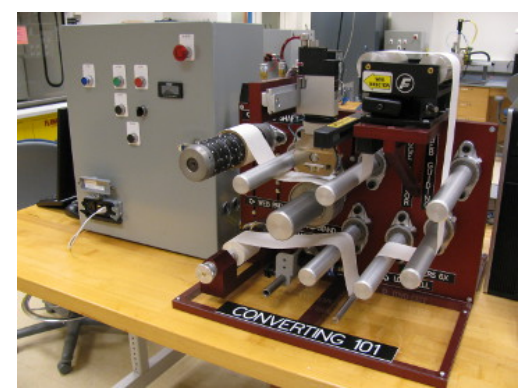

Web handling machine

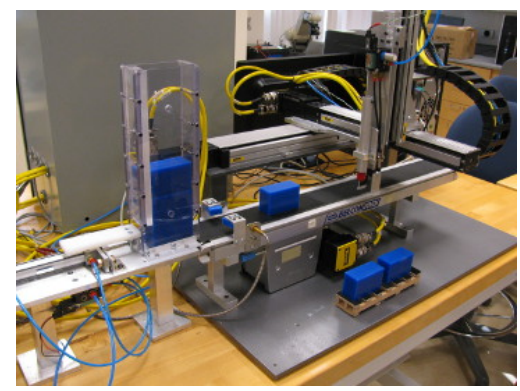

Part processing conveyor system

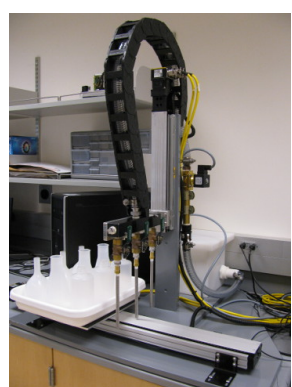

Bottle filling machine

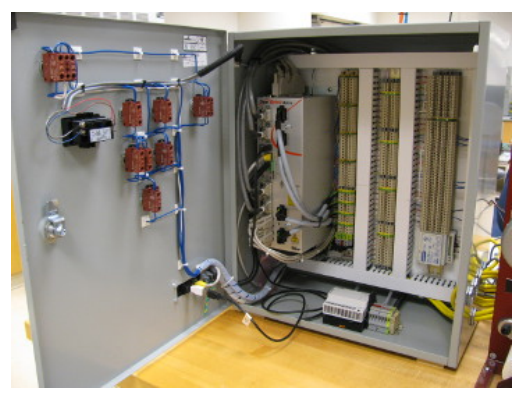

Control panel

Figure 3. Sample laboratory machines that were custom designed and built at Washington State University Vancouver.

\section{IV.1. Laboratory modules}

The laboratory modules of the curriculum were developed based on a competency model. Each module allows the students to individually work through a series of exercises to gradually develop their practical skills with the equipment. At the end of a module, the students are given a mastery test where they individually demonstrate their competency in using the equipment. Table 3 lists the laboratory modules and the competencies developed by each module.

The overall design of each module is based on the following structure:

1. Instructional content on a specific topic and the associated competencies to be developed,

2. Examples that walk through step-by-step interactions with the equipment, and

3. One or more "your turn" exercises where limited details are provided on a task to be completed with the lab machine.

Students come to the lab well prepared by studying the module in great detail. When they arrive in the lab, each student immediately goes to a workstation and starts going through the module materials. As each student works through the module, they are constantly working with the machine, trying "what-if" scenarios to complete the exercises in the module but also to explore their own ideas to satisfy their curiosity. Throughout the lab session, the students interact with the instructor frequently to either get help with the equipment or often to ask follow up questions after trying their own "what-if" ideas. 
Table 3. Laboratory modules.

\begin{tabular}{lll}
\hline & Module & Content \\
\hline 1 & Manual operation & $\begin{array}{l}\text { Activate/deactive motors, open/close control loops, } \\
\text { jogging axes, position and machine I/O monitoring }\end{array}$ \\
& & $\begin{array}{l}\text { Basic PLC program structure, enabling/disabling } \\
\text { PLCs, sample logic control programs, file } \\
\text { organization }\end{array}$ \\
& PLC programs & $\begin{array}{l}\text { Coordinate systems, motion program structure, } \\
\text { running/stopping motion programs, multi-tasking } \\
\text { with PLCs, sample motion programs }\end{array}$ \\
& Motion programs & Electronic camming, time-base control, sample \\
& & master/slave applications, setting up ECT
\end{tabular}

Table 4. Manual operation laboratory module.

\begin{tabular}{|c|c|c|}
\hline Content & Competency & Exercises \\
\hline Activating motors & $\begin{array}{l}\text { Issuing terminal commands to the } \\
\text { controller to phase and activate motors, } \\
\text { monitor motor status }\end{array}$ & $\begin{array}{l}\text { - One detailed exercise } \\
\text { - Your turn exercise }\end{array}$ \\
\hline $\begin{array}{l}\text { Activating closed loop } \\
\text { control }\end{array}$ & $\begin{array}{l}\text { Issuing terminal commands to open or } \\
\text { close position loops around each motor }\end{array}$ & $\begin{array}{l}\text { - One detailed exercise } \\
\text { - } \quad \text { Your turn exercise }\end{array}$ \\
\hline Jogging axes & $\begin{array}{l}\text { Commands to jog individual axes } \\
\text { through fixed distances, to a certain } \\
\text { position and jogging multiple axes at } \\
\text { once }\end{array}$ & $\begin{array}{l}\text { - Two detailed exercises } \\
\text { - } \quad \text { Your turn exercise }\end{array}$ \\
\hline Position monitoring & $\begin{array}{l}\text { Setting up unit conversions to monitor } \\
\text { real-time position of each axis in } \\
\text { various units ( } \mathrm{such} \text { as in } / \mathrm{s}, \mathrm{mm} / \mathrm{s} \text {, cts/s) }\end{array}$ & $\begin{array}{l}\text { - One detailed exercise } \\
\text { - Your turn exercise }\end{array}$ \\
\hline Plotting & $\begin{array}{l}\text { Capturing real-time motion data and } \\
\text { generating plots of kinematics variables }\end{array}$ & $\begin{array}{l}\text { - One detailed exercise } \\
\text { - } \quad \text { Your turn exercise }\end{array}$ \\
\hline Monitoring machine I/O & $\begin{array}{l}\text { Terminal commands to monitor } \\
\text { machine inputs, changing status of } \\
\text { machine outputs }\end{array}$ & $\begin{array}{l}\text { - Two detailed exercises } \\
\text { - } \quad \text { Your turn exercise }\end{array}$ \\
\hline Homing & $\begin{array}{l}\text { Setting up parameters and motion } \\
\text { profiles for homing an axis }\end{array}$ & $\begin{array}{l}\text { - Two detailed exercises } \\
\text { - } \quad \text { Your turn exercise }\end{array}$ \\
\hline
\end{tabular}

The instructor does not impose any time limitations such as finishing the first 5 exercises in the first week of the laboratory. Instead, the students are told they have two weeks to get through the entire module and it is their responsibility to manage their time on the laboratory equipment. No access is given to the laboratory outside the regular lab sessions. They are reminded that at the 
end of the two-week period they will have to demonstrate their competencies during a mastery test individually.

Table 4 lists the competencies developed by the "Manual Operation" module. The module supports the path generation lectures with hands-on exercises specific to trajectory programming with the machines. But it also contains additional skills such as monitoring machine $\mathrm{I} / \mathrm{O}$ that are needed in the later modules of the laboratory sequence. Detailed examples are distributed throughout each module. "Your Turn" exercises give the students a chance to self-evaluate what they just learned in the module.

\section{IV.2. Mastery test}

After a lab module was completed, a mastery test was given in the following week's lab session. Each student worked at a workstation individually just like the regular lab sessions. The mastery test is a closed-book test. The questions are designed to test all or most of the competencies that should have been developed by the completed module. Students have to use the equipment to find the answers for some of the questions. In other questions, they have to construct the correct commands to the controller or make changes in the parameter settings of the machine.

At the end of the exam, the instructor went to each workstation and asked the student to demonstrate the solutions for a couple of the questions. The student had to issue commands to the machine while the instructor was observing or had to explain changes in the settings by pointing at various parts of the software on the screen or by putting the machine through a specific motion to demonstrate the effect of the new settings. The instructor graded the entire test right there and provided immediate feedback to the student.

\section{Results and Discussion}

The new curriculum was offered by Prof. H. Gurocak for the first time in Fall 2013 in the Mech 467 "Automation" course at Washington State University Vancouver. The course had 20 mechanical engineering senior students. The class met for two 50-minute lectures and a 150minute lab session weekly. Each module comprised a minimum of two lectures and one lab.

Prior to the lecture that started a module, students individually completed "before" surveys to assess self perceptions of their initial levels of ability to perform certain tasks illustrating concepts critical to the module. At the end of the module, the same survey was distributed as the "after" survey (see Appendix).

Both surveys used a 5-point Likert scale. The scale ranged from 1-5, where 1= strongly disagree, $2=$ disagree, $3=$ neutral, $4=$ agree, and $5=$ strongly agree.

At the end of each module, students each took a mastery test to determine cognitive ability related to targeted module learning outcomes.

Figure 4 and Table 5 show the average point changes of the "before" and "after" lecture surveys for the Path Generation module. The range of the average point change between pre and post lectures was lowest for question 2 at 1.55, which asked students to sketch motion profiles and highest for question 3 (a 2.35 point change), which asked students to identify the differences between trapezoidal and S-curve velocity profiles. Question 4, which asked students to describe differences between slew and interpolated motion in a multi-axis system and question 5, which asked students to calculate parameters for interpolated motion of two axes to finish 
simultaneously, showed the second most average change pre and post lecture set (2.2 point change for both).

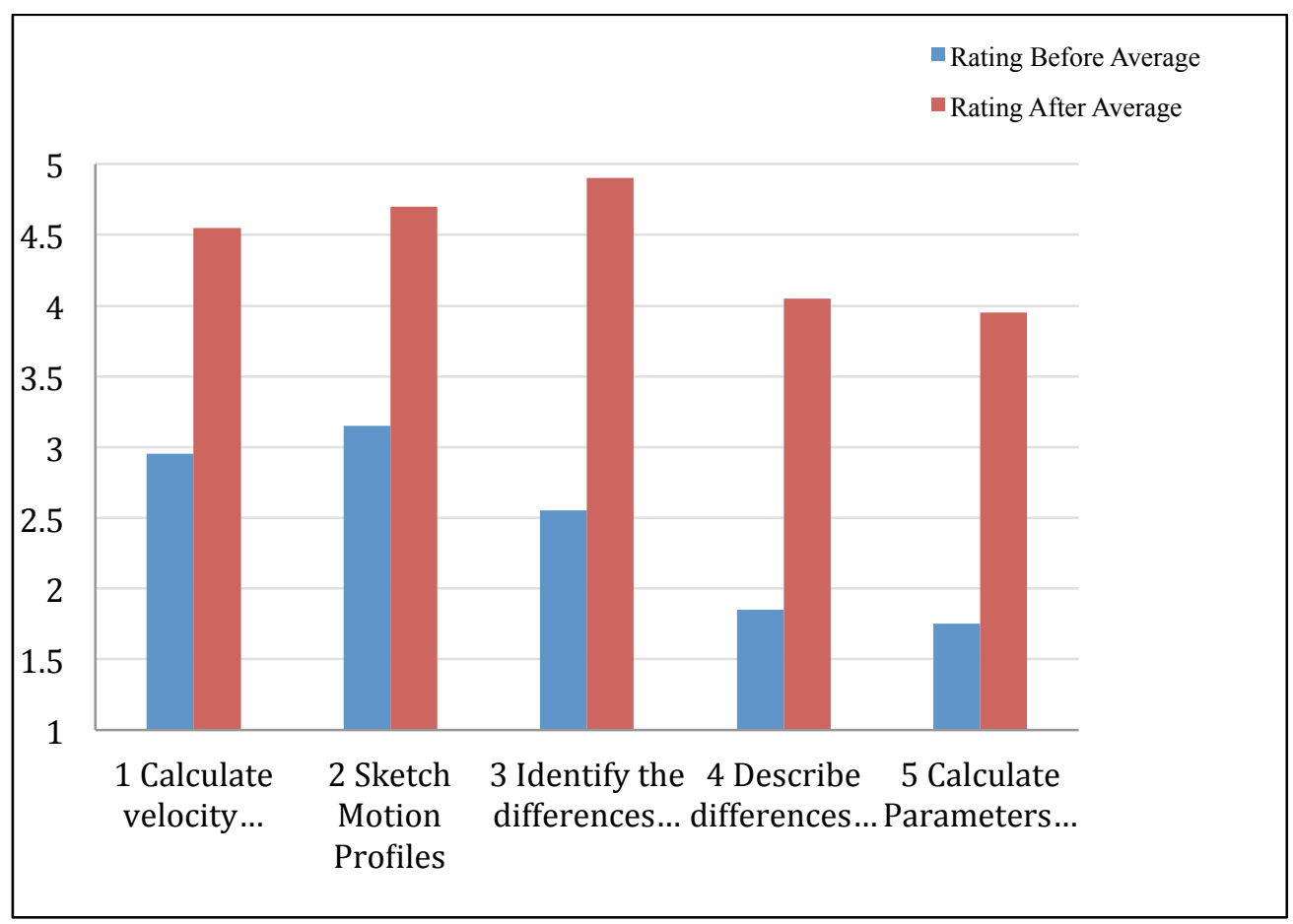

Figure 4. Average Point Change Before and After Path Generation Lectures.

Table 5. Average ratings for each question before and after lectures and average point change.

\begin{tabular}{lccc} 
Survey Question & $\begin{array}{c}\text { Rating "Before" } \\
\text { Average }\end{array}$ & $\begin{array}{c}\text { Rating "After" } \\
\text { Average }\end{array}$ & $\begin{array}{c}\text { Average Point } \\
\text { Change }\end{array}$ \\
\hline 1 & 2.95 & 4.55 & 1.6 \\
2 & 3.15 & 4.7 & 1.55 \\
3 & 2.55 & 4.9 & 2.35 \\
4 & 1.85 & 4.05 & 2.2 \\
5 & 1.75 & 3.95 & 2.2 \\
\hline \hline Overall Average & $\mathbf{2 . 4 5}$ & $\mathbf{4 . 4 3}$ & $\mathbf{1 . 9 8}$ \\
Minimum & $\mathbf{1 . 7 5}$ & $\mathbf{3 . 9 5}$ & $\mathbf{2 . 2}$ \\
Maximum & $\mathbf{3 . 1 5}$ & $\mathbf{4 . 9}$ & $\mathbf{1 . 7 5}$
\end{tabular}

Students reported an increase in their perceived ability to perform tasks critical to the Path Generation module learning outcomes. Furthermore, we noticed that the average value in all questions after the module varied only between strongly agree (5) and agree (4). The overall average rating before the module was 2.45 (disagree) indicating their perceived lack of ability to perform the tasks targeted by each question. The overall average went up to 4.43 (between strongly agree and agree) after the module. Prior to the module, students felt they had some prior ability to perform tasks targeted in questions 1 though 3 , but were not confident, as is indicated by the near neutral scores (2.55, 2.95 and 3.15). 
Figure 5 and Table 6 show the scores of the "before" and "after" surveys for the Path Generation lab. Students perceived ability to perform specific lab tasks after the lab had been completed ranged from the lowest average change of 2.95 points for lab performance task 4 , which asked students to transfer motion data to Excel to the highest of 3.6 points, for lab performance task 1, which asked students to phase and activate motors, open/close loops.

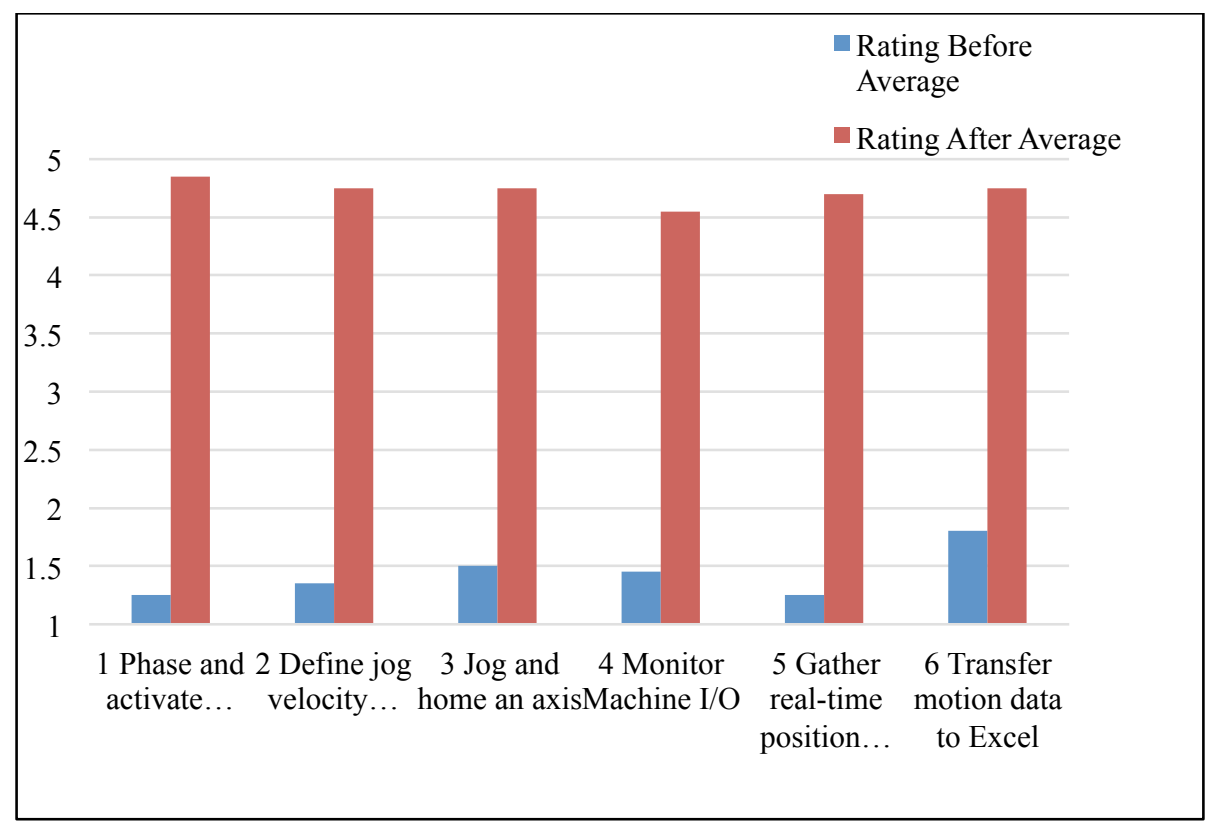

Figure 5. Average Point Change Before and After Path Generation Labs.

Table 6. Average ratings for each question before and after labs and average point change.

\begin{tabular}{lccc} 
Survey Question & $\begin{array}{c}\text { Rating "Before" } \\
\text { Average }\end{array}$ & $\begin{array}{c}\text { Rating "After" } \\
\text { Average }\end{array}$ & $\begin{array}{c}\text { Average Learning } \\
\text { Gains }\end{array}$ \\
1 & 1.25 & 4.85 & 3.6 \\
2 & 1.35 & 4.75 & 3.4 \\
3 & 1.5 & 4.75 & 3.25 \\
4 & 1.45 & 4.55 & 3.1 \\
5 & 1.25 & 4.7 & 3.45 \\
6 & 1.8 & 4.75 & 2.95 \\
\hline \hline Overall Average & $\mathbf{1 . 4 3}$ & $\mathbf{4 . 7 3}$ & $\mathbf{3 . 2 9}$ \\
Minimum & $\mathbf{1 . 2 5}$ & $\mathbf{4 . 5 5}$ & $\mathbf{3 . 3}$ \\
Maximum & $\mathbf{1 . 8}$ & $\mathbf{4 . 8 5}$ & $\mathbf{3 . 0 5}$
\end{tabular}

As illustrated in Table 6, students indicated not having prior knowledge and hands-on skills targeted by the lab (ratings in the $1.25-1.8$ range). Students reported significant perceived ability to perform specific tasks after the lab was completed. All ratings after the lab module are in the strongly agree range.

At the end of the Path Generation module, students completed an 8-question mastery test to directly assess key competencies. In this test, if a student could demonstrate his/her competency 
in a skill tested by a question, a score of "1" was given. If any mistakes were made during the hands-on skill demonstration or in the answer they found after working on the lab machine, a score of " 0 " was given.

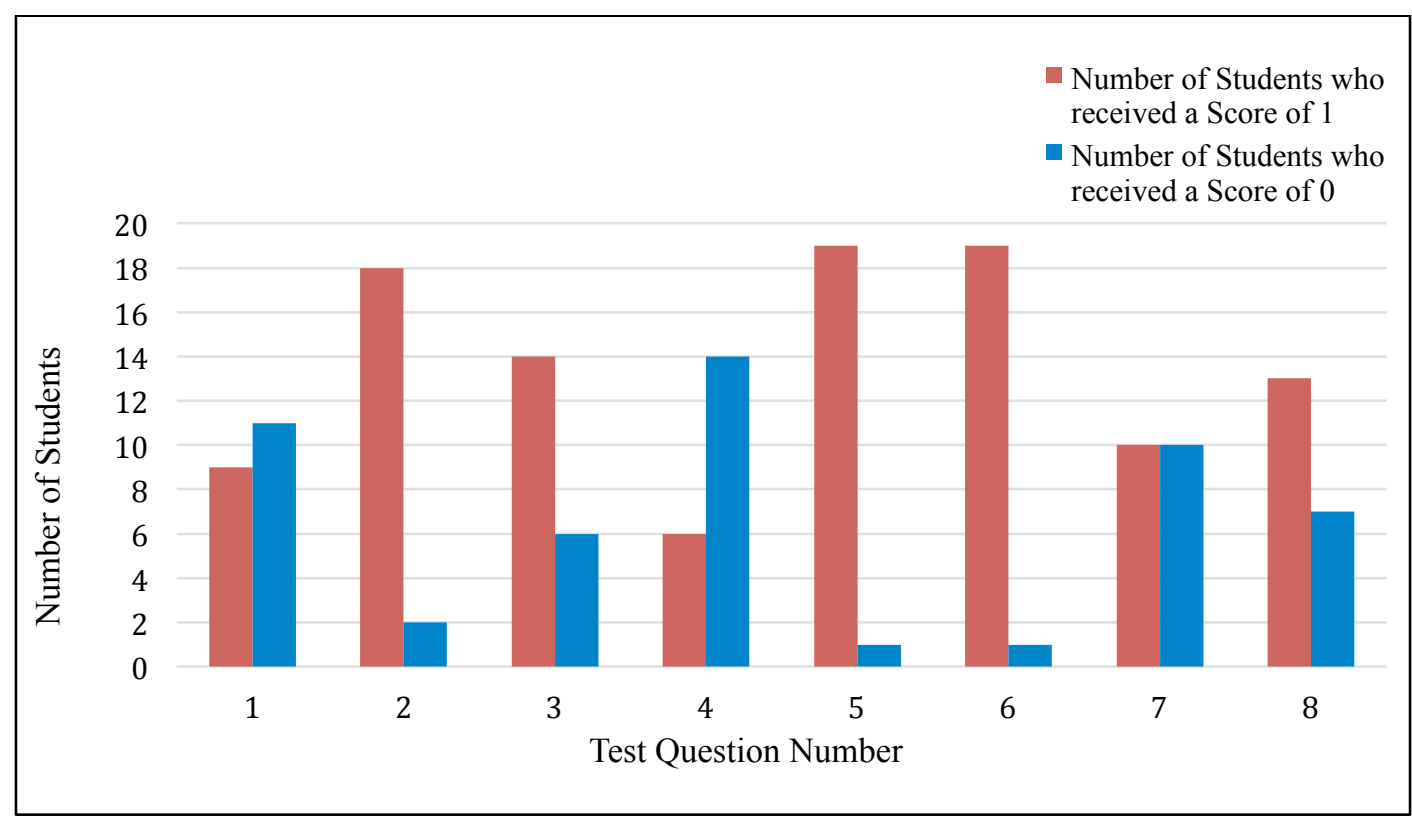

Figure 6. Number of Students Who Received 0 or 1 on the Path Generation Mastery Test.

Table 7. Average scores for mastery test for the Path Generation Module

\begin{tabular}{lc} 
Question & Average Scores \\
\hline 1 & 0.45 \\
2 & 0.9 \\
3 & 0.7 \\
4 & 0.3 \\
5 & 0.95 \\
6 & 0.95 \\
7 & 0.5 \\
\hline 8 & 0.65 \\
\hline Overall Average & $\mathbf{0 . 6 8}$ \\
Minimum & $\mathbf{0 . 3}$ \\
Maximum & $\mathbf{0 . 9 5}$
\end{tabular}

Eighteen out of 20 students received a 1 on question 2; and 19 out of 20 received a 1 on questions 4 and 5. Students performed the worst on question 4, with 14 students out of 20 receiving a 0. Question 1 also challenged students, with 11 out of 20 receiving a 0 and question 7 , where scores were split equally between 0 and 1 . Figure 6 shows scores for all mastery test questions. Table 7 shows the average scores for the mastery test.

As mentioned earlier, the lab supported and extended the path generation lectures with hands-on exercises specific to trajectory programming with the machines. But it also contained additional 
skills needed in the later sessions of the laboratory sequence. Table 8 shows the mapping between the survey and mastery test questions.

Table 8 . Targeted competencies by the mastery test questions and their mapping to the survey questions (Appendix).

\begin{tabular}{|c|c|c|c|c|}
\hline & \multirow{2}{*}{$\begin{array}{l}\text { Mastery } \\
\text { test } \\
\text { questions }\end{array}$} & \multirow[t]{2}{*}{ Targeted competencies by the mastery test } & \multicolumn{2}{|c|}{ Path Generation survey questions } \\
\hline & & & Lecture & Lab \\
\hline \multirow{4}{*}{ 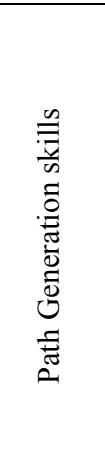 } & 2,6 & $\begin{array}{l}\text { Issue various motion commands to the lab } \\
\text { machine to achieve a certain jogging motion and } \\
\text { to capture real-time motion data to verify motion } \\
\text { profiles against the required parameters. }\end{array}$ & 1,2 & $2,5,6$ \\
\hline & 3 & $\begin{array}{l}\text { Program a desired motion profile into the motion } \\
\text { controller. }\end{array}$ & 1 & 2 \\
\hline & 4 & $\begin{array}{l}\text { Program the motion of an axis and calculate how } \\
\text { long it would travel at the programmed speed. }\end{array}$ & 1,3 & 2 \\
\hline & 7 & $\begin{array}{l}\text { Convert units so that the encoder data from the } \\
\text { system can be displayed in different units such as } \\
\text { in } \mathrm{mm} / \mathrm{sec} \text {, in } / \mathrm{sec} \text { or cts } / \mathrm{sec} \text {. }\end{array}$ & & 2,4 \\
\hline 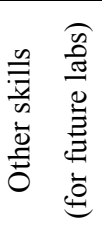 & $1,5,8$ & $\begin{array}{l}\text { Activate/deactivate motors, phase motors, } \\
\text { Jog axes to certain positions or through certain } \\
\text { distances, } \\
\text { Change homing speed of an axis. }\end{array}$ & & $1,3,4$ \\
\hline
\end{tabular}

Students had some prior knowledge of the basic kinematics for path generation ("before" questions 1, 2, 3 in Figure 4) but did not know anything about how to apply it to an actual machine ("before" questions 2, 5, 6 in Figure 5). After the lecture and lab modules were completed, their competency went up significantly ("after" questions 1, 2, 3 in Figure 4 and "after" questions 2, 5, 6 in Figure 5). They were able to demonstrate significant improvement in their applied skills during the mastery test (questions 2, 6 in Figure 6).

In question 3 of the mastery test, 14 out 20 students demonstrated the skill correctly. Even though this rating is slightly lower than those for questions 2 and 6 on the test, it also indicates the effectiveness of the module's lectures and labs.

Question 4 on the mastery test is where the performance was worst as only 6 out of 20 students could demonstrate their competency in this question. Although most of them could program the motion correctly, they made calculation mistakes in the second part of the problem, which led to a score of " 0 " for most of them.

Question 7 of the mastery test was about unit conversions so that the encoder data from the system could be displayed in different units such as in $/ \mathrm{sec}, \mathrm{mm} / \mathrm{sec}$, or cts/sec. Interestingly, students struggled with this task. Only 10 out of 20 completed the task correctly.

Based on these results, the lab module was updated to incorporate additional exercises/examples on unit conversions and kinematics calculations. 


\section{Conclusions}

In this paper, we presented an overview of a new mechatronics curriculum designed in partnership with industry to "teach the fundamentals", but in the context of industrial motion control technology and multi-axis machines. The details of one of its modules along with assessment results and feedback from students have also been presented.

Our goal was to complement the existing controls and mechatronics curricula. The curriculum differs from the current practice in controls and mechatronics courses because it uses an integrated approach using contemporary industrial motion control technology and multi-axis real world applications. Custom laboratory workstations were designed and built. Each station has a professionally wired control panel with an industrial motion controller. Machines are miniaturized versions of the real industrial machines.

The instructional design includes active learning components in the lectures and competencybased lab modules. The "your turn" active learning activities were conducted during lectures for 2-5 minutes. Students were given a problem and asked to work on it with the friend next to them. Then, the solution was discussed. The laboratory modules are based on a competency model. Each module allows the students to individually work through a series of exercises to gradually develop their practical skills with the equipment. At the end of a module, the students are given a mastery test where they individually demonstrate their competency in using the equipment.

The curriculum was offered by Prof. H. Gurocak for the first time in Fall 2013 in the Mech 467 "Automation" course at Washington State University Vancouver University. Student performance was assessed through "before" and "after" surveys for each lecture module and through master tests after lab modules.

Results of the Path Generation module indicated that both the lectures and labs led to significant perceived and real learning gains. In some of the topics targeted by the lectures, students indicated some prior knowledge (such as in basic kinematics) but did not feel confident about it. After the module was completed, all of their responses went up to the average rating of 4.43/5.00. The lab activities led to very significant perceived learning gains, as the students did not have any prior knowledge or hands-on skills with the laboratory equipment. After the lab was completed, the average ratings increased to 4.73/5.00. Most students demonstrated their competencies in several of the mastery test questions that followed the lab. Interestingly, in some of the basic skills such as unit conversions and basic kinematics calculations some of them struggled. Since the test was scored as " 1 " for completely accurate answer and " 0 " otherwise, any small mistake in these competency questions lowered the overall average scores significantly.

The new approach in the lab proved to be very effective. Students came to each lab session very well prepared. Once in the lab, they worked actively and enthusiastically to get through the modules. Giving them a chance to do "what-if" explorations made them much more engaged, curious and excited about the course. No one was checking their email or messages on cell phones or wasting time by joking around as is often the case in lab session where students work in teams on a piece of equipment. In large classes, implementing this individualized approach with machines will be harder. Possible solutions may include having two students at each station, multiple lab sessions offered by a TA and opening the lab for extended periods where students come in on their own time to get through the modules. 


\section{Acknowledgements}

This material is based upon work supported by the National Science Foundation under Grant No. DUE-TUES-0941035. Any opinions, findings, and conclusions or recommendations expressed in this material are those of the authors and do not necessarily reflect the views of the National Science Foundation.

\section{References}

[1] Gurocak, H., "Mechatronics course with a two-tiered project approach," 2007 ASEE Annual Conference and Exposition.

[2] Giurgiutiu, V. and Mouzon, B., "Functional Modules for Teaching Mechatronics to non-EE Engineering Students," 2005 ASEE Annual Conference and Exposition.

[3] Pourboghrat, F., et. Al., "Enhancing mechatronics education using model- based techniques and Mathworks tools," 2011 ASEE Annual Conference and Exposition.

[4] Rogers, J., Rabb, R., Korpela, C. and Ebel, R. "Learning mechatronics through graduated experimentation," 2007 ASEE Annual Conference and Exposition.

[5] Krishnan, M., et.al., "Advanced mechatronics: development of a course on sensors \& actuators for mechatronic systems," 2006 ASEE Annual Conference and Exposition.

[6] Surgenor, B., Firth, K., Wild, P., "Lessons Learned from a Mobile Robot Based Mechatronics Course," 2005 ASEE Annual Conference and Exposition.

[7] Brennan, S. "Mechatronics and systems instruction across graduate, undergraduate, and research applications using rapidly reconfigurable hardware," 2007 ASEE Annual Conference and Exposition. 
APPENDIX: Path Generation survey questions.

\begin{tabular}{|c|c|c|c|c|c|}
\hline \multicolumn{6}{|l|}{ I am able to: } \\
\hline & $\begin{array}{c}\text { Strongly } \\
\text { Disagree } \\
1\end{array}$ & $\begin{array}{l}\text { Disagree } \\
2\end{array}$ & $\begin{array}{c}\text { Neutral } \\
3\end{array}$ & $\begin{array}{c}\text { Agree } \\
4\end{array}$ & $\begin{array}{c}\text { Strongly } \\
\text { Agree } \\
5\end{array}$ \\
\hline \multicolumn{6}{|l|}{ LECTURES } \\
\hline \multicolumn{6}{|c|}{$\begin{array}{l}\text { 1. Calculate velocity, acceleration and position of a single axis, } \\
\text { given a set of known parameters }\end{array}$} \\
\hline \multicolumn{6}{|c|}{$\begin{array}{l}\text { 2. Sketch motion profiles (position, velocity and acceleration } \\
\text { plots) }\end{array}$} \\
\hline \multicolumn{6}{|c|}{$\begin{array}{l}\text { 3. Identify the differences between trapezoidal and S-curve } \\
\text { velocity profiles }\end{array}$} \\
\hline \multicolumn{6}{|c|}{$\begin{array}{l}\text { 4. Describe differences between slew and interpolated motion in } \\
\text { a multi-axis system }\end{array}$} \\
\hline \multicolumn{6}{|c|}{$\begin{array}{l}\text { 5. Calculate parameters for interpolated motion of two axes to } \\
\text { finish simultaneously }\end{array}$} \\
\hline \multicolumn{6}{|l|}{ LAB } \\
\hline \multicolumn{6}{|c|}{ 1. Phase and activate motors, open/close loops } \\
\hline \multicolumn{6}{|l|}{ 2. Define jog velocity parameters } \\
\hline \multicolumn{6}{|l|}{ 3. Jog and home an axis } \\
\hline \multicolumn{6}{|l|}{ 4. Monitor machine $\mathrm{I} / \mathrm{O}$} \\
\hline \multicolumn{6}{|c|}{$\begin{array}{l}\text { 5. Gather real-time position, velocity and acceleration data from } \\
\text { the controller and make a plot }\end{array}$} \\
\hline 6. Transfer motion data to Excel & & & & & \\
\hline
\end{tabular}

